\title{
Solution-Processed Ni-Based Nanocomposite Electrocatalysts: An Approach to Highly Efficient Electrochemical Water Splitting
}

\author{
Jaume Noguera-Gómez, ${ }^{\perp}$ Miguel García-Tecedor, ${ }^{\perp}$ Juan Francisco Sánchez-Royo, \\ Luisa María Valencia Liñán, María de la Mata, Miriam Herrera-Collado, Sergio I. Molina, \\ Rafael Abargues,* and Sixto Giménez*
}

Cite This: ACS Appl. Energy Mater. 2021, 4, 5255-5264

Read Online

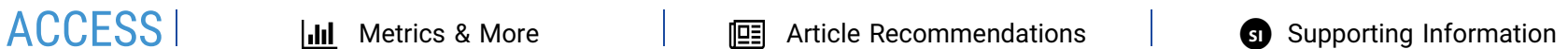

ABSTRACT: In this study, we report an up-scalable and low-cost solution-processed method to in situ synthesize an earth-abundant nonstoichiometric $\mathrm{NiO}_{x}$-based electrocatalytic film for water oxidation. The catalytic activity was found to be inversely proportional to the baking temperature, which varied from 50 to $500{ }^{\circ} \mathrm{C}$. We found the formation of a hybrid nanocomposite thin film of $\mathrm{NiO}_{x}$ nanocrystals $(<2 \mathrm{~nm}$ size) inside an acetate-based organic matrix at low temperatures $\left(<200{ }^{\circ} \mathrm{C}\right)$. The defective and short-range structural order of the $\mathrm{NiO}_{x}$-based nanocomposite electrocatalysts, compatible with lattice stress, low electrical conductivity, and high density of catalytically active surface species, and higher $\mathrm{Fe}$ incorporation were responsible for the enhanced electrocatalytic activity. Our champion $\mathrm{NiO}_{x}$ catalyst features a $358 \mathrm{mV}$

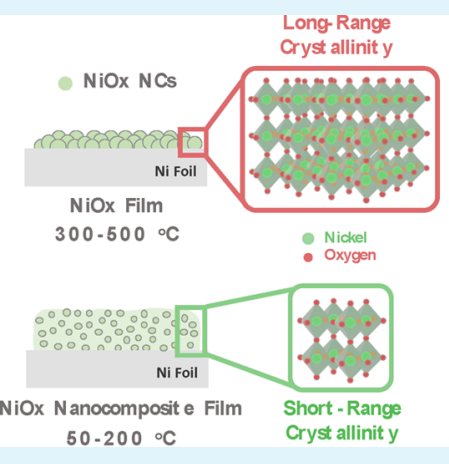

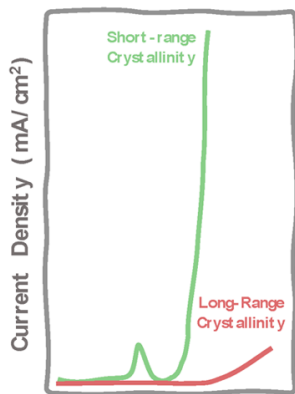

V vs RHE (V) overpotential at $10 \mathrm{~mA} \mathrm{~cm}{ }^{-2}$ and more than $60 \mathrm{~h}$ of continuous operation without significant losses, which is a remarkable milestone for undoped $\mathrm{NiO}_{x}$ electrocatalysts synthesized at nearly room temperature by a solution-processed up-scalable method.

KEYWORDS: electrocatalyst, $\mathrm{NiO}_{x}$-based nanocomposite, water splitting, solution processing

\section{INTRODUCTION}

The development of sustainable, fossil-free strategies to synthesize fuels and added-value chemicals has raised enormous interest in the last years to provide reliable energy vectors and the feedstocks needed for the chemical industry at a global scale. ${ }^{1-3}$ One of the most promising alternatives involves the use of renewable electricity (i.e., wind, solar, and hydropower) to power electrochemical conversion processes, which convert abundant molecules (e.g., water, carbon dioxide, and nitrogen) into higher-value products (e.g., hydrogen, hydrocarbons, oxygenates, and ammonia). In all these processes, water oxidation stands out as the preferred reaction to provide the protons and electrons needed for the target reduction reactions, although this process is considered a kinetic bottleneck, and consequently, the development of electrocatalytic materials that effectively oxidize water is essential for improving the efficiency of the overall electrochemical conversion process. ${ }^{4}$

Currently, the most efficient water oxidation catalysts (WOCs) are based on iridium and ruthenium oxides, $\mathrm{IrO}_{2}$ and $\mathrm{RuO}_{2}$, which operate in acidic/neutral conditions and are the preferred choice for the state-of-the-art polymer electrolyte membrane (PEM) electrolyzers. ${ }^{5,6}$ However, the high cost and scarceness of these materials justify the intensive search for electrocatalytic materials based on earth-abundant elements and low-cost synthetic processes to find sustainable and costeffective alternatives. First-row transition metals oxides (Ni, $\mathrm{Co}, \mathrm{Fe}$, and $\mathrm{Mn}$ ) afford a promising alternative to $\mathrm{IrO}_{2}$ and $\mathrm{RuO}_{2}$ as WOCs. Among them, Ni-based materials constitute one of the best choices due to their high electrocatalytic activity and stability under alkaline conditions, related to their high electrical conductivity and corrosion resistance. ${ }^{7,8}$ Indeed, large-scale commercial liquid alkaline (LA) electrolyzers preferentially use nickel-based anodes. ${ }^{9,10}$ Furthermore, the solution processing of oxide semiconductors is an exciting fabrication method to improve the efficiency and decrease costs by direct-writing and high-throughput roll-to-roll printing technologies such as inkjet printing and flexography.

Several strategies have been proposed for the synthesis of Ni-based anodes, such as pulsed laser deposition, ${ }^{11}$ sputtering, ${ }^{12}$ electrodeposition, ${ }^{13,14}$ chemical vapor deposition, ${ }^{15}$ and sol-gel method. ${ }^{16}$ Among them, low-temperature processed

Received: March 16, 2021

Accepted: April 27, 2021

Published: May 10, 2021 
materials have shown the highest activity toward oxygen evolution reaction (OER). Berlinguette et al. reported a lowtemperature photochemical metal-organic deposition, leading to amorphous mixed metal oxide films based on $\mathrm{NiO}_{x}$ for OER electrocatalysis. ${ }^{17} \mathrm{Liu}$ et al. introduced a room-temperature solution multistep procedure to grow an amorphous nickeliron alloy catalyst on $\mathrm{Ni}$ foam for water oxidation that outperforms its crystalline counterpart. The same authors reported a ball-milling method to synthesize a NiFe hydroxide catalyst, inducing lattice tensile strain, which enhanced the adsorption of oxygenated intermediates for water splitting. ${ }^{18}$ Similarly, Zhou et al. reported the synthesis of amorphous mesoporous $\mathrm{Ni} / \mathrm{Fe}$ (oxy)hydroxide [(Ni,Fe)OOH] films on $\mathrm{Ni}$ foam by room-temperature mechanical stirring processing with an exceptional activity and durability toward OER. ${ }^{19}$ Sargent et al. developed a room-temperature synthesis to produce gelled $\mathrm{Fe}, \mathrm{Co}$, and $\mathrm{Ni}$ oxyhydroxide materials with high-valence transition-metal distribution (i.e., W, Mo, Nb, Ta, and $\mathrm{Re}$ ), reporting a $\sim 17$-fold mass activity enhancement compared to that for the OER catalysts widely employed in industrial water-splitting electrolyzers. ${ }^{20}$ More recently, Duan et al. reported non-stoichiometric $\mathrm{NiO}_{x}$ nanocrystals with unusual activity and stability, stemming from the high density of defects combined with oxygen atoms to form $\mathrm{NiOOH}$ species. ${ }^{21}$ Shudo et al. also reported a $3 \mathrm{D}$ porous $\mathrm{Ni} / \mathrm{NiO}_{x}$ bifunctional oxygen electrocatalyst derived from freeze-dried $\mathrm{Ni}(\mathrm{OH})_{2}$ with exceptional activity. The stacking of $2 \mathrm{D}$ sheets into $3 \mathrm{D}$ mass seemed to play a vital role behind this excellent bifunctionality of freeze-dried $\mathrm{Ni} / \mathrm{NiO}_{x^{*}}{ }^{22}$ Although these electrocatalysts offer excellent OER catalytic performance, most of the synthetic approaches rely on multistep procedures with severe limitations to be compatible with industrial fabrication methods for large-scale production.

Here, we report a low-temperature, straightforward, and fast synthetic method with an extraordinary ability to in situ generate homogeneous $\mathrm{Ni}$-based electrocatalytic thin films from a precursor solution by spin-coating and compatible with different industrial printing techniques such as inkjet printing and slot-die coating. ${ }^{23}$ Remarkably, this in situ synthesis approach can be easily integrated into scale-up processes like roll-to-roll printing for large-area and cost-effective mass production. The low baking temperatures employed are particularly beneficial since these allow deposition onto flexible plastic substrates, which cannot be processed above $150{ }^{\circ} \mathrm{C}$ without compromising the excellent film adherence over different materials, resulting in homogeneous catalytic electrodes. The OER activity of the as-synthesized electrocatalysts was proportional to the density of structural/electronic defects, which increases at lower baking temperatures, together with $\mathrm{Fe}$ incorporation, leading to a competitive undoped $\mathrm{NiO}_{x}$ catalyst with $358 \mathrm{mV}$ of overpotential at $10 \mathrm{~mA} \mathrm{~cm}^{-2}$ and more than $60 \mathrm{~h}$ of continuous operation without significant losses.

\section{EXPERIMENTAL METHODS}

2.1. Materials. Nickel acetate tetrahydrate $\left(\mathrm{Ni}(\mathrm{OAc})_{2} \cdot 4 \mathrm{H}_{2} \mathrm{O}, 98 \%\right.$ Alfa Aesar), 2-methoxyethanol (MeOEtOH, 99\%, Fisher Chemical), and monoethanolamine (MEA, Sigma Aldrich) were used as delivered without further purification.

2.2. Preparation of $\mathrm{NiO}_{x}$-Based Electrocatalyst. $\mathrm{NiO}_{x}$ thin films were synthesized by a one-step sol-gel procedure. We used $\mathrm{Ni}(\mathrm{OAc})_{2} \cdot 4 \mathrm{H}_{2} \mathrm{O}$, as a precursor of $\mathrm{NiO}_{x}, \mathrm{MeOEtOH}$ as a solvent, and MEA as a chelating and stabilizer agent. Before deposition, $1 \mathrm{~cm}^{2}$ of nickel foil (99.6\% purity, from US Solid, Ohio) was ultrasonicated in a $3 \mathrm{M} \mathrm{HCl}$ solution for $10 \mathrm{~min}$, rinsed with 3:1 isopropanol/acetone, and dried with compressed air. Then, the $\mathrm{Ni}$ foil was exposed to a $\mathrm{UV} /$ ozone cleaning for $10 \mathrm{~min}$ (Ossila Ozone Cleaner). The typical $\mathrm{NiO}_{x}$ precursor formulation consists of a solution of $0.9 \mathrm{M} \mathrm{Ni}(\mathrm{OAc})_{2}$ and 0.9 M MEA in MeOEtOH. The precursor solution was aged in a dry bath block for $15 \mathrm{~min}$ at $60^{\circ} \mathrm{C}$. During this process, subsequent hydrolysis and polycondensation reactions of $\mathrm{Ni}(\mathrm{OAc})_{2}$ in $\mathrm{MeOEtOH}$ led to the formation of a stable sol of Ni-oxo-acetate and/or Ni-hydroxo-acetate species of different sizes. As a result of the formation of a sol, the viscosity of the precursor solution increased. Here, the presence of MEA as a chelating ligand is critical to control the kinetics of the polycondensation and avoid the transition from sol to gel before the deposition step. Afterward, this solution was spincoated on the $\mathrm{Ni}$ foil (or FTO substrate) at $2000 \mathrm{rpm}$ for $30 \mathrm{~s}$ and soft-baked at $50{ }^{\circ} \mathrm{C}$ for $30 \mathrm{~min}$ on a hot plate to remove MEA and $\mathrm{MeOEtOH}$. Finally, the sample was baked in air at different temperatures from 50 to $500{ }^{\circ} \mathrm{C}$ for $30 \mathrm{~min}$. The thickness of the $\mathrm{NiO}_{x}$ film on the $\mathrm{Ni}$ foil and FTO substrate after spin-coating is identical for a given baking temperature, indicating that a similar amount of the electrocatalyst is coated on the electrode. The overall process for the synthesis of the electrocatalyst is shown in Supporting Information, Figure S1.

2.3. Structural, Optical, and Electrical Characterization. Field emission scanning electron microscopy (SEM) performed with an S-4800 instrument from HITACHI (Tokyo, Japan) operating at 20 $\mathrm{kV}$ was used for the morphological characterization of the samples. Their crystalline structure was assessed by X-ray diffraction (XRD) collected on a Bruker D8 Advanced X-ray diffractometer with copper $\mathrm{K}_{\alpha}$ radiation $(\lambda=1.5418 \AA)$ operating at a grazing incidence of $1^{\circ}$, at a scan rate of $5^{\circ} \cdot \mathrm{min}^{-1}$ for $2 \theta$ angles ranging from 20 to $80^{\circ}$. The chemical composition of the resulting electrocatalytic electrodes was investigated by confocal multi-spectral imaging (CMSI) Raman spectroscopy and X-ray photoelectron spectroscopy (XPS). The Raman measurements were performed with a WITec Apyron confocal microscope using a $532 \mathrm{~nm}$ laser with a $40 \mathrm{~mW}$ power, a grating of 1800 lines $/ \mathrm{mm}$, a spectrometer of $300 \mathrm{~mm}$, and an optical objective Zeiss EC Epiplan-Neofluar Dic 100×/0.9. X-ray photoelectron spectroscopy (XPS) was performed in an ultrahigh vacuum system (ESCALAB210; base pressure $1.0 \times 10^{-10} \mathrm{mbar}$ ) from Thermo VG Scientific. Samples were mounted on a conducting sample holder and introduced into the vacuum chamber. The measurements were taken over an area of $1 \mathrm{~mm}^{2}$. High-resolution transmission electron microscopy (HR-TEM) images were obtained using the model FEI TALOS F200X from ThermoFisher Scientific that combines highresolution S/TEM and TEM imaging with industry-leading energydispersive X-ray spectroscopy (EDX) signal detection and 3D chemical characterization with compositional mapping. Photoluminescence measurements were performed in a Horiba Jobin Yvon Fluorolog system. The electrical conductivity $(\sigma)$ was calculated with the Van der Pauw equation using the Keithley 2400 SourceMeter equipment to measure the electrical resistances $R_{1}$ and $R_{2}$ along the vertical and horizontal edges, respectively:

$$
e^{-\pi \cdot d \cdot R_{1} \cdot \sigma}+e^{-\pi \cdot d \cdot R_{2} \cdot \sigma}=1
$$

where $d$ is the thickness of the film. Four contacts were deposited with silver paint on the film surface.

2.4. Electrochemical Characterization of the Electrocatalysts. Linear sweep voltammetry (LSV) and cyclic voltammetry (CV) measurements were performed with the Autolab potentiostat/ galvanostat PGSTAT302 at 10 and $50 \mathrm{mV} / \mathrm{s}^{-1}$ scan rate, in a threeelectrode configuration cell, using a $\mathrm{Pt}$ wire as the counter electrode and a $\mathrm{Ag} / \mathrm{AgCl}(3 \mathrm{M} \mathrm{KCl})$ electrode as the reference. $\mathrm{A} 1 \mathrm{M} \mathrm{KOH}$ solution at $\mathrm{pH} 13.6$ (without $\mathrm{Fe}$ purification) was used as the electrolyte. All potentials were referred to the reversible hydrogen electrode (RHE) through the Nernst equation: $V_{\mathrm{RHE}}=V_{\mathrm{Ag} / \mathrm{AgCl}}+$ $V_{\mathrm{Ag} / \mathrm{AgCl}}^{0}+0.059 \cdot \mathrm{pH}$. The electrode/electrolyte contact area was 1 $\mathrm{cm}^{2}$. The turnover frequency (TOF) was calculated as TOF $=\frac{j_{\text {geo }}}{n q}$, where $j_{\text {geo }}$ is the geometrical current density at an overpotential of 400 $\mathrm{mV}$ (selected for comparison), $n$ is the number of electrons transferred during the reaction (for water oxidation, $n=4$ ), and $q$ 

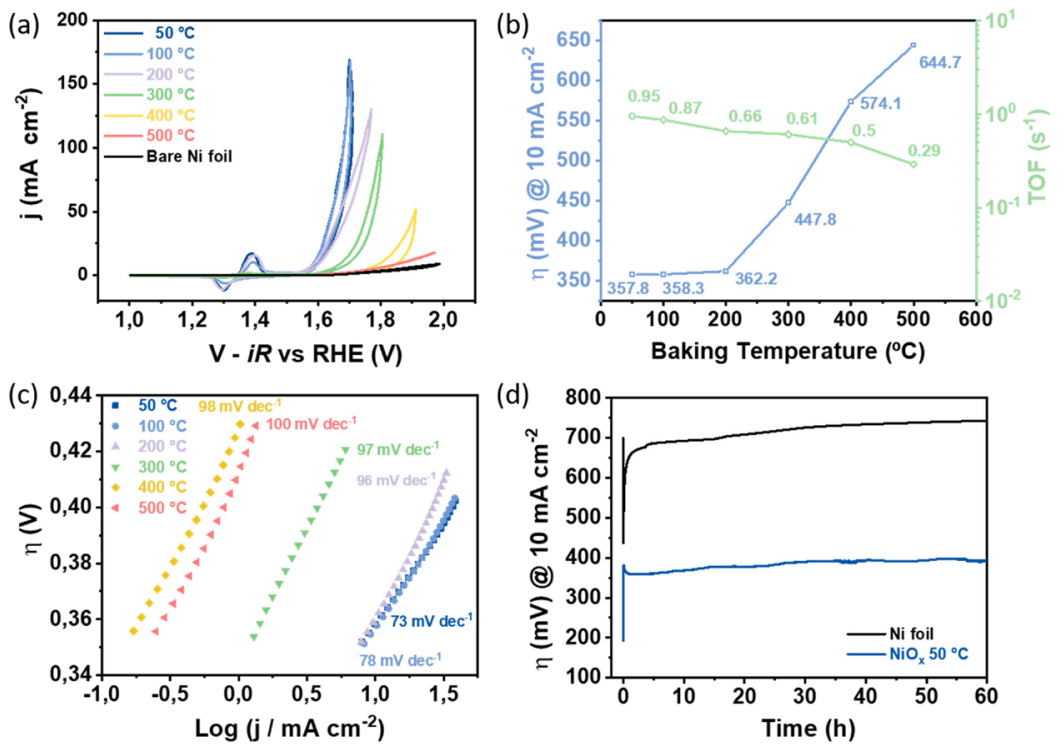

Figure 1. Electrochemical characterization of $\mathrm{NiO}_{x}$ films on a planar $\mathrm{Ni}$ substrate, baked at different temperatures in $\mathrm{KOH} 1 \mathrm{M}(\mathrm{pH} 13.6)$. (a) Cyclic voltammograms (iR corrected). (b) Overpotential (squares) at $10 \mathrm{~mA} \cdot \mathrm{cm}^{-2}$ and calculated TOF values (diamonds) at $400 \mathrm{mV}$ overpotential vs baking temperature. (c) Tafel analysis showing the Tafel slopes for the different baking temperatures. (d) Chronopotentiostatic test at $10 \mathrm{~mA} \cdot \mathrm{cm}^{-2}$ on the champion catalyst and reference Ni substrate (baked at $50{ }^{\circ} \mathrm{C}$ ).

is the integrated area under the cathodic redox wave divided by the scan rate. The $\mathrm{O}_{2}$ evolution at the electrocatalyst surface was determined by gas chromatography measurements using a sealed cell coupled to an Agilent Micro-GC gas chromatograph during a chronoamperometric measurement at $1.6 \mathrm{~V}$ vs RHE in $1 \mathrm{M} \mathrm{KOH}$ solution. The faradaic efficiency ( $\mathrm{FE}$ ) was estimated through the relation $\mathrm{FE}(\%)=\frac{\mathrm{O}_{2}(\exp )}{\left.\mathrm{O}_{2} \text { (theo }\right)} \cdot 100$, where $\mathrm{O}_{2}(\exp )$ is the amount of evolved $\mathrm{O}_{2}$ in mol, monitored every $5 \mathrm{~min}$, and $\mathrm{O}_{2}($ theo $)$ is the theoretical $\mathrm{O}_{2}$ evolution calculated with Faraday's Law: $n(\mathrm{~mol})=\frac{j_{\mathrm{O}_{2}} t}{n F}$ , where $j_{\mathrm{O} 2}$ is the current density recorded in the chronoamperometry measurement, $t$ is the time in seconds, $n$ is the number of electrons transferred in the reaction, and $F$ is the Faraday constant, 96,485.33 C $\mathrm{mol}^{-1}$.

Electrochemical impedance spectroscopy (EIS) measurements were performed between $0.1 \mathrm{~Hz}$ and $1 \mathrm{MHz}$ with $20 \mathrm{mV}$ of amplitude perturbation, with a step potential of $50 \mathrm{mV}$ in the anodic direction. The EIS raw data were analyzed with the ZView software (Scribner Associates), fitting the raw data to an equivalent circuit model for extracting both capacitances and resistances. With the extracted capacitance values from EIS, Mott-Schottky analysis was carried out using the following expression:

$$
\frac{1}{C_{\mathrm{SC}}^{2}}=\frac{2}{\varepsilon_{0} \varepsilon_{\mathrm{r}} e N_{\mathrm{A}} A^{2}}\left(\phi_{\mathrm{SC}}-\frac{k T}{e}\right) \text {, where } \phi_{\mathrm{SC}}=V-V_{\mathrm{FB}}
$$

$C_{\mathrm{SC}}$ represents space charge capacitance, $e$ is the elementary charge, $\varepsilon_{0}$ is the vacuum permittivity, $\varepsilon_{\mathrm{r}}$ is the relative permittivity of $\mathrm{NiO}_{x}$ (taken as 9.1), ${ }^{24} N_{\mathrm{A}}$ is the acceptor density, $A$ is the geometrical area, $k$ is the Boltzmann constant, and $T$ is the absolute temperature (taken as $298 \mathrm{~K}$ ). From this analysis, the values of the flat-band potential $\left(V_{\mathrm{FB}}\right)$ and the acceptor density $\left(N_{\mathrm{A}}\right)$ were extracted.

\section{RESULTS AND DISCUSSION}

$\mathrm{NiO}_{x}$ nanocomposite films spin-coated on planar Ni substrates were tested as water oxidation electrocatalysts in $1 \mathrm{M} \mathrm{KOH}$ solution ( $\mathrm{pH}$ 13.6) after baking at different temperatures between 50 and $500{ }^{\circ} \mathrm{C}$. The cyclic voltammograms in Figure 1a clearly show the significant impact of the baking temperature on the electrocatalytic performance, leading to a systematic increase in the catalytic current upon decreasing the temperature. The baking step after the coating is necessary to enhance the adhesion of the thin film onto the substrate since unbaked films were not mechanically stable (not shown). The well-known redox wave related to the reversible reaction $\mathrm{Ni}(\mathrm{OH})_{2}+\mathrm{OH}^{-} \leftrightharpoons \mathrm{NiOOH}+\mathrm{H}_{2} \mathrm{O}+e^{-}$, characteristic of the Ni-based electrocatalysts, can be observed between 1.2 and 1.5 $V_{\mathrm{RHE}}{ }^{25}$ Higher peak intensities were correlated to lower temperatures. At $50{ }^{\circ} \mathrm{C}$, the recorded overpotential from linear sweep voltammetry (LSV; Supporting Information, Figure S2) at $10 \mathrm{~mA} \cdot \mathrm{cm}^{-2}$ reached $358 \mathrm{mV}$, as shown in Figure $1 \mathrm{~b}$. The turnover frequency (TOF) at a $400 \mathrm{mV}$ overpotential, which reflects the amount of evolved molecular oxygen per mole of the catalyst per second, was also strongly dependent on the baking temperature, increasing upon decreasing the temperature, with the highest value $\left(0.95 \mathrm{~s}^{-1}\right)$ at $50{ }^{\circ} \mathrm{C}$. Tafel analysis (from cyclic voltammograms of Figure 1a) shows lower Tafel slopes as the baking temperature decreases (Figure 1c). These results are consistent with enhanced water oxidation kinetics. ${ }^{26,27}$ At baking temperatures of $200-500{ }^{\circ} \mathrm{C}$, Tafel slopes around $100 \mathrm{mV} \cdot \mathrm{dec}^{-1}$ (close to $120 \mathrm{mV} \cdot \mathrm{dec}^{-1}$ ) suggest that the rate-determining step is the first electron transfer step in the reaction. Conversely, at $50-100{ }^{\circ} \mathrm{C}$, the Tafel slopes were around $78 \mathrm{mV} \cdot \mathrm{dec}^{-1}$, suggesting a change of the water oxidation mechanism, with the rate-determining step involving a chemical step after the first electron transfer. ${ }^{28}$ Chronopotentiostatic tests at $10 \mathrm{~mA} \cdot \mathrm{cm}^{-2}$ confirmed the long-term stability of the champion $\mathrm{NiO}_{x}$ films (Figure 1d), without any significant variation of the overpotential after $60 \mathrm{~h}$ of testing. The excellent film adherence onto the $\mathrm{Ni}$ substrate is believed to significantly account for this promising long-term stability, highlighting the competitive performance of an easily upscalable and stable earth-abundant water oxidation electrocatalyst solution-processed at nearly room temperature. Indeed, no degradation or surface amorphization was identified after operation. Furthermore, the Faradaic efficiency for oxygen evolution on the optimal electrocatalyst under operation reached $100 \%$ after $1 \mathrm{~h}$ of testing, as shown in Supporting Information, Figure S3. The overpotential and 
stability of our low-cost and up-scalable electrocatalysts are competitive with those of other reported pure $\mathrm{NiO}_{x}$-based electrocatalysts, as shown in Supporting Information, Table S1.

A detailed structural and spectroscopic characterization was carried out to understand the origin of the electrocatalytic performance of the synthesized materials. SEM investigation revealed minor morphological changes in the $\mathrm{NiO}_{x}$ nanocomposite films for different baking temperatures (Supporting Information, Figure S4). A more detailed morphological and crystalline characterization was obtained by HRTEM (Figure 2). Negligible differences were observed between 50 and 100

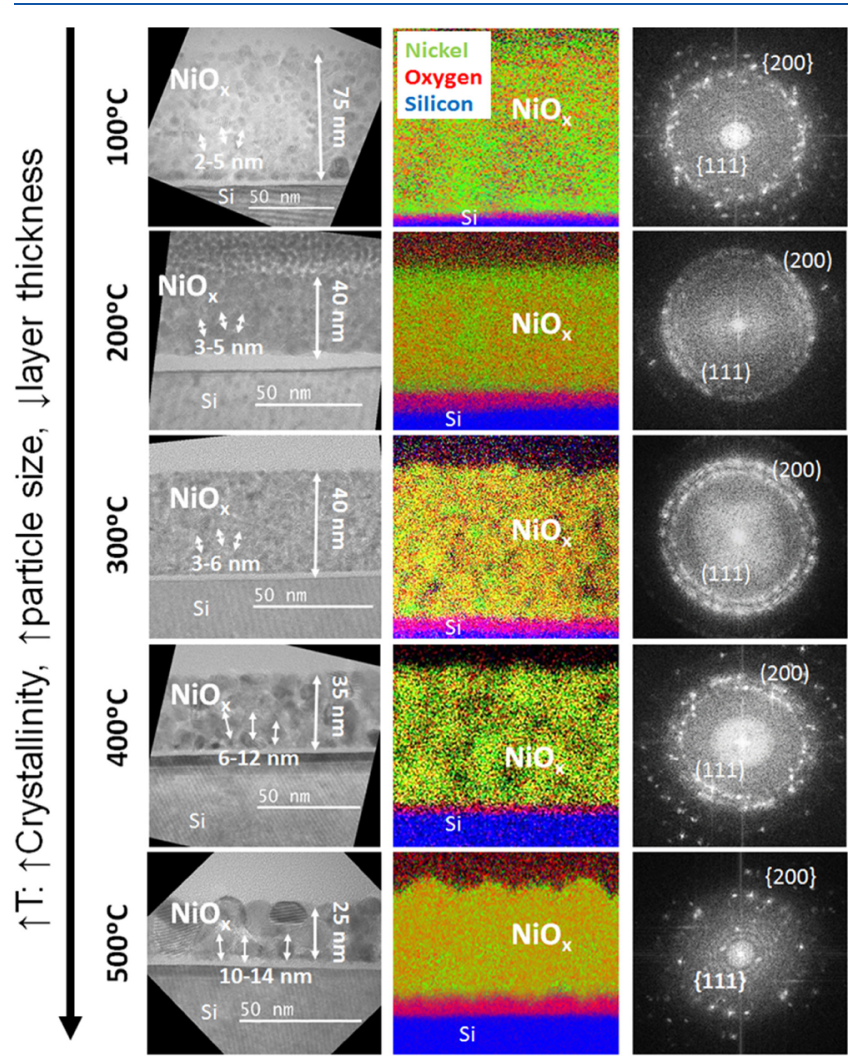

Figure 2. (S)TEM characterization of the $\mathrm{NiO}_{x}$ films on $\mathrm{Si}$ substrates, synthesized at different temperatures $\left(100-500{ }^{\circ} \mathrm{C}\right)$ : HRTEM images showing film thickness and particle size (left), the corresponding EDS maps ( $\mathrm{Ni}, \mathrm{O}$, and $\mathrm{Si}$ displayed in green, red, and blue, respectively) of the samples (middle), and FFTs showing (111) and (200) $\mathrm{NiO}_{x}$ atomic planes (right).

${ }^{\circ} \mathrm{C}$ baked films, and only results at $100{ }^{\circ} \mathrm{C}$ are shown here. $\mathrm{NiO}_{x}$ films appear as polycrystalline layers at any baking temperature. Crystal growth is promoted with temperature as expected, and HRTEM images show a noticeable increase in the mean crystallite size from $<2 \mathrm{~nm}$ at $100{ }^{\circ} \mathrm{C}$ up to $14 \mathrm{~nm}$ at $500{ }^{\circ} \mathrm{C}$ (Figure 2, left panel and Supporting Information, Figure S5), in good correspondence with XRD results (Figure $3 \mathrm{a}, \mathrm{d}$ ), which clearly show the progressive development of crystalline domains within the nanocomposite films with baking temperature.

Indeed, the X-ray diffractograms of the $\mathrm{NiO}_{x}$ films baked at $300-500{ }^{\circ} \mathrm{C}$ showed three significant peaks corresponding to the (111), (200), and (220) crystal planes of the $\mathrm{NiO}$ cubic structure (JCPDS 78-0423), ${ }^{29}$ but no crystalline peaks were observed below $300{ }^{\circ} \mathrm{C}$ (Figure 3a), suggesting the short-range structural order of these films. The different crystallinities of
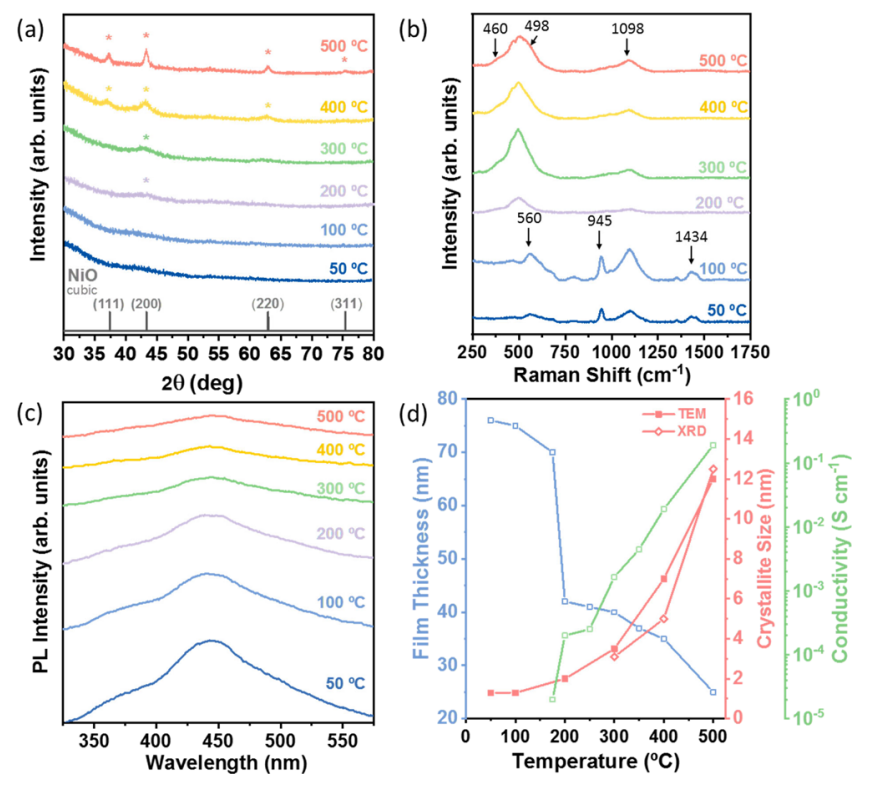

Figure 3. (a) XRD, (b) Raman, and (c) PL measurements on the $\mathrm{NiO}_{x}$ samples baked at different temperatures $\left(50-500{ }^{\circ} \mathrm{C}\right)$. (d) Evolution of the film thickness, crystalline size (from XRD and TEM), and electrical conductivity with the baking temperature.

the samples are also evident from the electron diffraction patterns or calculated fast Fourier transforms (FFTs), where the $\{111\}$ and $\{200\}$ planes can be identified (Figure 2, right panel). The EDS chemical analyses allow the mapping of the $\mathrm{Ni}$ and $\mathrm{O}$ distribution within the films (Figure 2, middle panel). Additionally, their estimated thickness by HAADFSTEM measurements (Supporting Information, Figure S5) decreases monotonically with the baking temperature from 75 $\mathrm{nm}$ at $100{ }^{\circ} \mathrm{C}$ down to $25 \mathrm{~nm}$ at $500{ }^{\circ} \mathrm{C}$. This effect relates to the more efficient thermal decomposition of organic compounds (mainly acetates and methoxyethanol) at higher temperatures, in agreement with the TGA results (Supporting Information, Figure S6). Therefore, a compositional transition from an organic-inorganic hybrid nanocomposite is observed where $\mathrm{NiO}_{x} \mathrm{NCs}$ are embedded inside an acetate matrix (at low temperatures) to an all-inorganic $\mathrm{NiO}_{x}$ film with a microstructure formed by round-shaped interconnected particles (at high temperature). Comparing the solid content of samples baked at low temperatures $\left(50,100\right.$, and $200{ }^{\circ} \mathrm{C}$ ) and high temperatures $\left(300,400\right.$, and $\left.500{ }^{\circ} \mathrm{C}\right)$, a constant wt. ratio of 2.7 is obtained, which is in good agreement with the theoretical 2.9 wt. ratio of $\mathrm{Ni}(\mathrm{OAc})_{2} / \mathrm{NiO}$ (Supporting Information, Table S2). This confirms that the solid content of thin films baked at low and high temperatures mainly corresponds to $\mathrm{Ni}(\mathrm{OAc})_{2}$ and $\mathrm{NiO}$, respectively. It must be noted that the large grain boundary area (related to the decrease in the crystallite size) and the higher concentration of short-range order domains within the films have been reported to enhance the electrocatalytic activity of metal oxide electrocatalysts, ${ }^{30-33}$ in excellent agreement with the performance metrics reported in Figure 1.

Complementary structural information was obtained with Raman spectroscopy of the as-prepared electrocatalysts (Figure $3 b)$. At the lowest baking temperatures $\left(50-100^{\circ} \mathrm{C}\right)$, different vibrational modes were observed at 560,945 , and $1434 \mathrm{~cm}^{-1}$. The presence of nickel acetate complexes is confirmed by peaks at $945 \mathrm{~cm}^{-1}\left(\mathrm{C}-\mathrm{C}\right.$ str) and $1434 \mathrm{~cm}^{-1}$ (C-O str)..$^{34}$ 
The peak located at $560 \mathrm{~cm}^{-1}$ is attributed to $\mathrm{Ni}-\mathrm{O}$ stretching. We observe that this peak gradually weakens in intensity with the decrease in the baking temperature (and hence with the crystal size), which is in good agreement with previous studies. $^{35}$ These results support the formation of an organicinorganic hybrid nanocomposite where $\mathrm{NiO}_{x} \mathrm{NCs}$ are embedded inside an acetate matrix. Conversely, at higher baking temperatures $\left(200-500{ }^{\circ} \mathrm{C}\right)$, the observed vibrational modes were located at 460, 498, and $1098 \mathrm{~cm}^{-1}$. All the observed peaks are associated with the $\mathrm{Ni}-\mathrm{O}$ stretching vibrational modes. ${ }^{36,37}$ On the other hand, the band located at 450-500 $\mathrm{cm}^{-1}$ increased with the baking temperature, reflecting the increase in the crystallinity of the material and confirming that a higher catalytic activity correlates to a higher fraction of short-range order domains. Additional evidence of the highly defective nature of the electrocatalysts baked at lower temperatures was obtained from photoluminescence (PL) measurements on the as-prepared samples deposited on glass substrates. The PL spectra of the different $\mathrm{NiO}_{x}$ films (and the glass substrate) are shown in Figure $3 c$, featuring a broad emission centered at $445 \mathrm{~nm}$ and ascribed to surface oxygen vacancies. ${ }^{38-40}$ Note that oxygen vacancies in metal oxides can also be monitored by other techniques like electron paramagnetic resonance, ${ }^{41,42}$ cathodoluminescence, ${ }^{43}$ transient absorption spectroscopy, ${ }^{44}$ spectroelectrochemistry, ${ }^{45}$ and impedance spectroscopy. ${ }^{46,47}$ Supporting Information, Figure S7 shows the PL spectra of the different $\mathrm{NiO}_{x}$ films and the glass substrate, where the shoulder at higher energies corresponds to the glass substrate $(\sim 375 \mathrm{~nm})$ and the radiative band-to-band emission expected at $335 \mathrm{~nm}$ (3.7 $\mathrm{eV}^{48,49}$ ) was not identified. Moreover, the observed emission peak intensity clearly decreased with the baking temperature (Figure 3c), confirming that the density of surface oxygen vacancies decreases with the baking temperature. Collectively, XRD, HRTEM, Raman, and PL results suggest that the catalytic activity of our $\mathrm{NiO}_{x}$ films scales with the density of structural defects (oxygen vacancies), in good agreement with previous studies. ${ }^{50,51}$ Figure $3 \mathrm{~d}$ shows the evolution of the film thickness, crystallite size (measured from XRD and HRTEM), and electrical conductivity with the baking temperature. The electrical conductivity increases from $2 \times 10^{-5}$ at $175^{\circ} \mathrm{C}$ to 0.1 $\mathrm{S} \cdot \mathrm{cm}^{-1}$ at $500{ }^{\circ} \mathrm{C}$ as a result of the transition from a hybrid $\mathrm{NiO}_{x}$ nanocomposite to an all-inorganic $\mathrm{NiO}_{x}$ film. Both the growth of the crystallite size of $\mathrm{NiO}_{x}$ and the elimination of the organic matrix (that leads to a significant decrease in the interparticle spacing within the $\mathrm{NiO}_{x}$ thin film) favor charge carrier transport within the film. ${ }^{52}$

Surface properties of the as-synthesized $\mathrm{NiO}_{x}$ films were also evaluated by X-ray photoelectron spectroscopy (XPS). Figure $4 \mathrm{a}, \mathrm{b}$ shows the XPS spectra at the energy region of the O 1 s and $\mathrm{Ni} 2 \mathrm{p}$ core levels measured in the samples baked from 50 to $500{ }^{\circ} \mathrm{C}$. Below $200{ }^{\circ} \mathrm{C}$, both core levels show a single component. Whereas the $\mathrm{O} 1 \mathrm{~s}$ has a singlet peak centered at $532.0 \mathrm{eV}$, Ni 2 p exhibits a spin-orbit doublet whose $j=3 / 2$ broad component lies at $856.5 \mathrm{eV}$ with a spin-orbit splitting of $17.7 \mathrm{eV}$. The Ni $2 \mathrm{p}$ main doublet is accompanied by a typical shake-up satellite located at $\sim 6 \mathrm{eV}$ from the main doublet to higher binding energies. The presence of these core levels is characteristic of $\mathrm{Ni}(\mathrm{II})$ species, which we attribute to $\mathrm{Ni}(\mathrm{OH})_{2} \cdot{ }^{53,54}$

At temperatures $\geq 200{ }^{\circ} \mathrm{C}$, both the $\mathrm{O} 1 \mathrm{~s}$ and $\mathrm{Ni} 2 \mathrm{p}$ spectra are red-shifted. The presence of new $\mathrm{O} 1 \mathrm{~s}$ and $\mathrm{Ni} 2 \mathrm{p}$ core-level components located at lower binding energies is observed. As
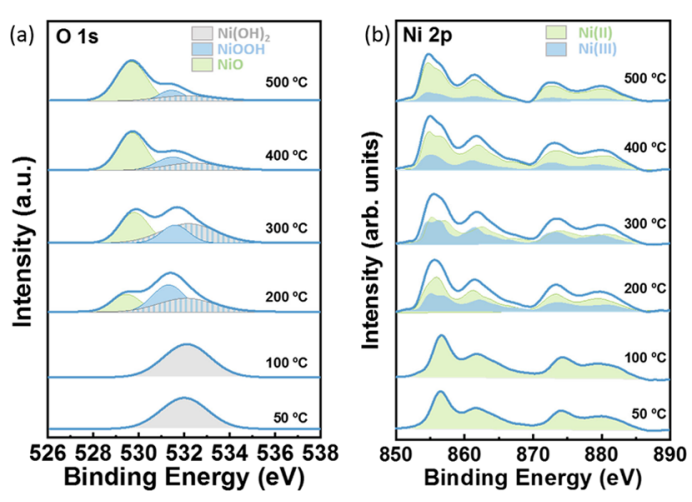

Figure 4. (a, b) O 1 s and Ni $2 p$ spectra were acquired by XPS in samples synthesized at different baking temperatures. The result of the deconvolution process for each specific spectrum is shown below each particular spectrum. The different $\mathrm{O} 1 \mathrm{~s}$ components identified have been identified by dashed vertical lines.

the baking temperature increases, the low binding-energy $\mathrm{O} 1 \mathrm{~s}$ peak becomes more intense at the expense of the broad peak. The deconvolution of the $\mathrm{O} 1 \mathrm{~s}$ spectra (Figure 4a) shows three singlets from $200{ }^{\circ} \mathrm{C}$. The one located at $532.1 \mathrm{eV}$ is attributed to $\mathrm{OH}^{-}$species, whereas the other two peaks located at 531.4 and $529.7 \mathrm{eV}$ are ascribed to the presence of $\mathrm{O}^{-2}$ species. The integrated intensity of the $\mathrm{O}^{-2}$ component located at $531.4 \mathrm{eV}$ and that of $\mathrm{OH}^{-}$located at $532.1 \mathrm{eV}$ show a $1: 1$ ratio for samples baked above $200^{\circ} \mathrm{C}$. This is indicative of the presence of $\mathrm{NiOOH}^{55}$ The third $\mathrm{O}^{-2}$ singlet, located at $529.7 \mathrm{eV}$, is assigned to $\mathrm{NiO} .{ }^{54-56}$ We can conclude that $\mathrm{Ni}(\mathrm{OH})_{2}$ is the main form of $\mathrm{Ni}(\mathrm{II})$ in the samples baked at $50-100{ }^{\circ} \mathrm{C}$. From $200{ }^{\circ} \mathrm{C}$, we observe the formation of non-stochiometric $\mathrm{NiO}$ with the formation of $\mathrm{Ni}(\mathrm{III})$ species in the form of $\mathrm{NiOOH}$ together with $\mathrm{Ni}(\mathrm{II})$ in the form of $\mathrm{Ni}(\mathrm{OH})_{2}$ and $\mathrm{NiO}$. Therefore, the deconvolution area of $\mathrm{OH}^{-}$in the $\mathrm{O}$ 1s spectra corresponds to both $\mathrm{Ni}(\mathrm{OH})_{2}$ and $\mathrm{NiOOH}$. As the baking temperature increases, $\mathrm{NiO}$ becomes the most dominant compound. A higher density of $\mathrm{Ni}$ (II) sites in the pristine material is consistent with the formation of $\mathrm{NiO}$, which converts into $\mathrm{Ni}(\mathrm{OH})_{2}$ upon immersion in the alkaline electrolyte solution and into the catalytically active $\mathrm{NiOOH}$ phase upon the application of anodic bias.

From XPS measurements, the surface oxygen vacancy ratio in the $\mathrm{NiO}_{x}$ samples can also be estimated (Supporting Information, Figure S8). From this analysis, it is clear that samples prepared at temperatures below $200{ }^{\circ} \mathrm{C}$ show an excess in $\mathrm{O}$ of around $20-40 \%$ attributable to adsorbed adventitious water. In contrast, samples prepared at higher temperatures (where the presence of adsorbed water is less probable) show a surface O vacancy ratio of $\sim 20 \%$, suggesting a surface $\mathrm{NiO}_{0.8}$ local configuration. These results align well with the hypothesis that bulk defect states may also participate in catalysis, as recently reported for amorphous electrocatalysts. ${ }^{57}$ Additionally, the more hydrophilic surface that resulted from low-temperature processing can be beneficial for electrocatalysis. More details on XPS spectra are provided in Supporting Information, Section S8.

Further mechanistic insights were obtained by impedance spectroscopy (IS). The density of catalytic sites has been used as a descriptor for catalytic activity, ${ }^{45}$ and there is a direct link between this quantity and the chemical capacitance, which can be determined by IS. ${ }^{58} \mathrm{NiO}_{x}$ films were deposited on FTO substrates, and the catalytic currents followed the same trends 
compared to those using the Ni substrate, although absolute values were significantly lower, as expected for a less conductive substrate (see Supporting Information, Figure S9a). The series resistance of $\mathrm{FTO} / \mathrm{NiO}_{x}$ is around $20 \Omega$ $\mathrm{cm}^{2}$ (Supporting Information, Figure S10), while that of $\mathrm{Ni}$ / $\mathrm{NiO}_{x}$ films is $9 \Omega \mathrm{cm}^{2}$. The experimental impedance data were fitted to a simple Randles circuit (Supporting Information, Figure S11) since only a single arc was observed in the Nyquist plots, and both resistances and capacitances were extracted. The resistances (Figure 5a), which are controlled by the charge
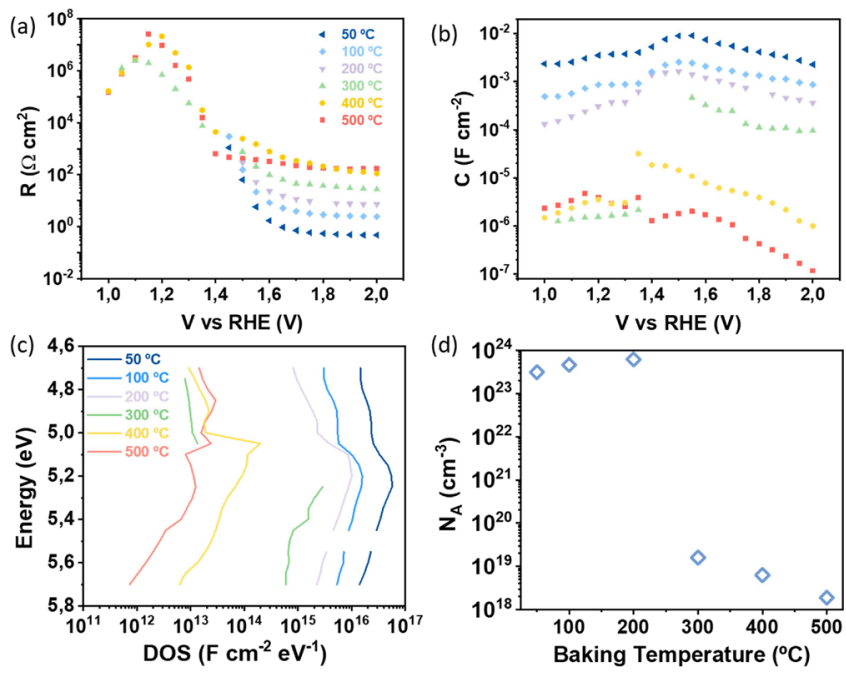

Figure 5. (a) Resistance $(R)$ and (b) capacitance $(C)$ vs applied potential, extracted from EIS measurements, for the analyzed samples. (c) Calculated DOS for the different films. (d) Acceptor density $\left(N_{\mathrm{A}}\right)$ vs baking temperature showing two clear regimes of carrier concentration. All results have been normalized to the electrochemical surface area (ECSA).

transfer kinetics, are directly correlated to the $j-V$ curves shown in Supporting Information, Figure S9a, through the expression $R_{\text {total }}=\left(\frac{\mathrm{d} j}{\mathrm{~d} V}\right)^{-1}$. Consequently, higher slopes of the catalytic currents are related to lower resistances. At relevant potentials for water oxidation (1.4-2 V vs RHE), the series resistance $\left(R_{\mathrm{s}}\right)$ controls the total resistance, and charge transfer kinetics does not limit the overall reaction. At moderate potentials (1-1.4 V vs RHE), the capacitance follows a MottSchottky dependence. Consequently, both flat-band potential $\left(V_{\mathrm{FB}}\right)$ and acceptor density $\left(N_{\mathrm{A}}\right)$ were estimated at each baking temperature, confirming the p-type behavior of the $\mathrm{NiO}_{x} /$ $\mathrm{Ni}(\mathrm{OH})_{2}$ catalytic films (Supporting Information, Figure S12), as previously reported. ${ }^{59}$ It has been reported that p-type behavior plays a beneficial role on electro-oxidation processes since a positively charged surface will attract negatively charged intermediates prone to water oxidation. ${ }^{60,61}$ Although $V_{\mathrm{FB}}$ does not show a clear trend with baking temperatures, $N_{\mathrm{A}}$ increases with lower baking temperatures, consistent with a higher density of structural/electronic defects, as recently reported for sputtered $\mathrm{NiO}_{x}$ films. ${ }^{58}$ At more anodic potentials $(1.4-2 \mathrm{~V}$ vs RHE), the capacitance increases with applied potential with a well-defined peak over the redox wave and a gradual decrease over the catalytic region, as shown in Supporting Information, Figure $\mathrm{S} 9 \mathrm{~b}$ for the $\mathrm{NiO}_{x}$ nanocomposite film baked at $50{ }^{\circ} \mathrm{C}$. This behavior has been recently observed on $\mathrm{NiO}_{x}$ electrocatalysts $^{58}$ and holds at each baking temperature (Figure $5 \mathrm{~b}$ ).
The capacitive peak over the region of the redox wave is associated with the bulk reversible transformation of $\mathrm{Ni}(\mathrm{OH})_{2}$ to $\mathrm{NiOOH}$ before the onset of catalysis. The decrease in capacitance at the catalytic region is ascribed to the decreased hole population due to hole injection to the solution. Furthermore, the exponential increase in the capacitance with film thickness is typical of a chemical capacitance, ${ }^{62}$ from which an approximate density of states (DOS) can be calculated since $C=e \cdot$ DOS (Figure 5c). ${ }^{63}$ This procedure has been successfully employed on different materials like $\mathrm{TiO}_{2}{ }^{62}$ silicon, ${ }^{64}$ conducting polymers, ${ }^{65}$ etc. The obtained DOS, in good agreement with previous reports for highly defective $\mathrm{Ni}(\mathrm{OH})_{2} / \mathrm{NiOOH}$ electrocatalysts, ${ }^{58}$ reflects an increase in the density of catalytic sites for films baked at lower temperatures, with a higher density of structural/ electronic defects (oxygen vacancies) as confirmed by XRD, TEM, Raman, conductivity, and PL.

Furthermore, it has been recently reported that amorphous $\mathrm{Ni}$-based catalysts can expose bulk catalytic active sites, leading to a higher OER activity, while their crystalline counterpart only exposes surface sites. ${ }^{57}$ Our XPS results are consistent with this behavior, and to further understand this behavior, the electrochemical surface area (ECSA) of the $\mathrm{NiO}_{x}$ films baked at the different temperatures was assessed by cyclic voltammograms at the non-faradaic region (1.1-1.2 V vs RHE). The results, shown in Supporting Information, Figures S13 and S14 and Table S3, reflect an increase in the surface area with the baking temperature, clearly indicating that the higher catalytic currents obtained at low temperatures are not related to higher surface area but to enhanced catalytic activity.

The acceptor density $\left(N_{\mathrm{A}}\right)$ vs the baking temperature is shown in Figure 5d. Two different regimes can be observed below and above $200{ }^{\circ} \mathrm{C}$, also observed in XPS measurements. Below $200{ }^{\circ} \mathrm{C}$, the acceptor density of the $\mathrm{NiO}_{x}$ films was 2 orders of magnitude higher compared to those baked at higher temperatures due to the higher concentration of oxygen vacancies, responsible for the higher catalytic activity toward water oxidation. Oxygen vacancies have been found to dramatically enhance the catalytic activity of several metal oxides for different added-value chemical reactions such as oxygen evolution reaction, ${ }^{66}$ oxygen reduction reaction, ${ }^{67} \mathrm{~N}_{2}$ reduction, ${ }^{68}$ and methanol oxidation, ${ }^{69}$ among others. Their role in the final performance of (photo)electrocatalytic materials and devices is critical for the design of novel electrocatalysts. Specifically for OER, the concentration and location of oxygen vacancies within the crystalline lattice have been found to correlate to the final performance of the (photo)electrocatalysts ${ }^{70,71}$ by increasing the density of catalytic sites, ${ }^{72}$ improving the electronic conductivity, ${ }^{73}$ and promoting the adsorption of $\mathrm{OH}^{-}$species onto lowcoordinated metals. ${ }^{74}$ Here, the concentration of oxygen vacancies was found to increase when decreasing the baking temperature, leading to a less stoichiometric cubic $\mathrm{NiO}$ phase and a concomitant increase in the density of short-range order domains and active catalytic sites, as observed by the higher intensity of the $\mathrm{Ni}(\mathrm{II}) / \mathrm{Ni}$ (III) redox wave and the increase in the acceptor density of 2 orders of magnitude. These effects can also be probably related to a favorable modification of the electronic environment of $\mathrm{Ni}$ centers, compatible with lattice tensile stress, which has been related to a more favorable adsorption of oxygenated intermediates for water splitting. ${ }^{18}$ All these factors led to a dramatic enhancement of the OER activity of the $\mathrm{NiO}_{x}$ catalysts baked at temperatures below 200 
${ }^{\circ} \mathrm{C}$, providing a nearly room-temperature solution-processed method to deliver highly competitive electrocatalysts for water oxidation.

Finally, it is well known that unintentional Fe incorporation from the unpurified $\mathrm{KOH}$ electrolyte solution plays a key role in the electrocatalytic activity of Ni-based catalysts, which cannot be neglected. ${ }^{75,76}$ A higher Fe concentration was indirectly detected by Raman spectroscopy in the films baked at lower temperatures. Fe incorporation, as an impurity in the host $\mathrm{Ni}$ lattice, improves the OER activity by providing active sites modifying the local $\mathrm{Ni}$ environment. ${ }^{7,77}$ The Raman spectra of the electrocatalytic films baked at 50 and $300{ }^{\circ} \mathrm{C}$ after OER can be observed in Supporting Information, Figure S15a. These films were deposited on FTO substrates, which account for the vibrational modes located at 244, 285, 470, and $630 \mathrm{~cm}^{-1}$ associated with the rutile vibrational modes $E_{\mathrm{u}}, E_{\mathrm{g}}$, and $A_{1 \mathrm{~g}}$, respectively, present in $\mathrm{SnO}_{2} \cdot{ }^{78-80}$ After the normalization of the Raman spectra of both materials (Supporting Information, Figure S15b), the band at 498 $\mathrm{cm}^{-1}$ associated to $\mathrm{Ni}-\mathrm{O}$ vibrations is more clearly defined for the electrocatalyst baked at a higher temperature. Additional vibrational modes at 470 and $690 \mathrm{~cm}^{-1}$ were identified after baking at $50{ }^{\circ} \mathrm{C}$. The first peak has been associated with the $E_{\mathrm{g}}$ mode in $\mathrm{SnO}_{2}$, as detailed above, while the second peak accounts for $\mathrm{Fe}-\mathrm{O}$ vibrations in OER electrocatalysts. ${ }^{81}$ This higher $\mathrm{Fe}$ incorporation, together with the higher concentration of oxygen vacancies, synergistically interacts to provide the observed enhanced catalytic activity toward water oxidation for the electrocatalysts baked at lower temperatures $\left(<200{ }^{\circ} \mathrm{C}\right) .^{76}$

Scheme 1 summarizes the general correspondence between synthesis, structure, and performance for the different baking

Scheme 1. Schematic Illustration of the Evolution Process from the Spin-Coated Deposition of the Sol-Gel Synthetic Non-stoichiometric $\mathrm{NiO}_{x}$ Films to the Crystalline (Cubic $\mathrm{NiO}$, Obtained with the Vesta Software) and Amorphous Samples Annealed above and below $200{ }^{\circ} \mathrm{C}$, Respectively
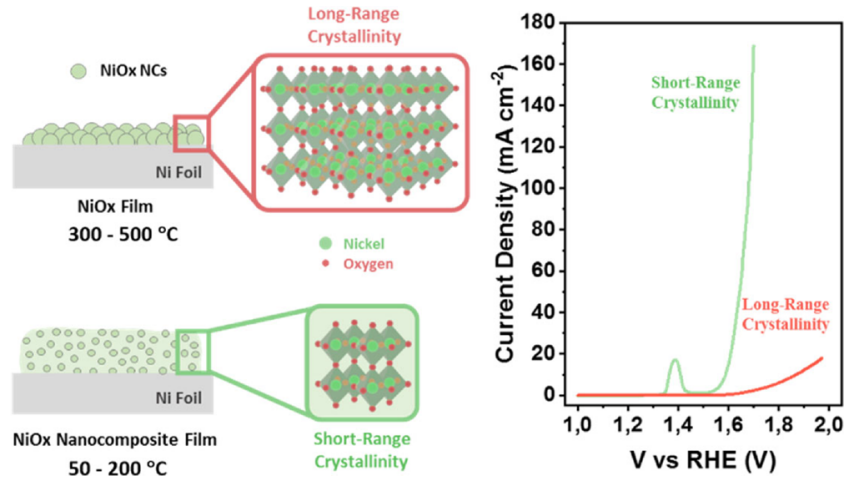

conditions tested. The short-range crystallinity of the organicinorganic nanocomposite films processed at lower temperatures $\left(50-200{ }^{\circ} \mathrm{C}\right)$, compatible with lattice stress, low electrical conductivity, and high density of defects/catalytically active surface species, and higher $\mathrm{Fe}$ incorporation are responsible for the very competitive electrocatalytic performance of the material toward water oxidation.

\section{CONCLUSIONS}

A straightforward, solution-processed method has been developed for the in situ synthesis of an organic-inorganic nanocomposite thin film of $\mathrm{NiO}_{x}$ nanocrystals embedded in an acetate-based organic matrix as a competitive low-cost and upscalable electrocatalyst for water oxidation. The reaction takes place after spin-coating during a soft bake at low temperatures $\left(50-200{ }^{\circ} \mathrm{C}\right)$, allowing control of the film thickness, crystallinity, and electrical conductivity of the nanocomposite through the baking conditions. The $\mathrm{NiO}_{x}$-based nanocomposite thin film coated on the $\mathrm{Ni}$ foil showed a promising electrocatalytic performance when baked at low temperature $\left(50{ }^{\circ} \mathrm{C}\right)$, reflected on a competitive OER overpotential (358 $\mathrm{mV}$ at $\left.10 \mathrm{~mA} \cdot \mathrm{cm}^{-2}\right)$ in alkaline conditions $(\mathrm{pH}=13.6)$ for more than $60 \mathrm{~h}$ without significant degradation. The small size of the $\mathrm{NiO}_{x} \mathrm{NCs}(2-5 \mathrm{~nm})$ accounts for the high density of crystalline/electronic defects, compatible with lattice stress, low conductivity, and high density of catalytically active surface species, and higher $\mathrm{Fe}$ incorporation prompting a more efficient, robust, and economic OER nickel-based electrocatalyst. This synthetic strategy, combined with relevant guidelines for catalyst design and optimization, may pave the way for the future design of highly efficient, durable, and economically competitive water oxidation electrocatalysts to be used in a wide range of electrosynthetic applications.

\section{ASSOCIATED CONTENT}

\section{Supporting Information}

The Supporting Information is available free of charge at https://pubs.acs.org/doi/10.1021/acsaem.1c00776.

Scheme of the synthetic method; electrochemical and structural (SEM and TEM) characterization of the $\mathrm{NiO}_{x}$ films; oxygen evolution and faradaic efficiency; TGA, PL, XPS, impedance, and Raman spectroscopy measurements; ECSA and Mott-Schottky analysis; and benchmarking information (PDF)

\section{AUTHOR INFORMATION}

\section{Corresponding Authors}

Rafael Abargues - UMDO, Instituto de Ciencia de los Materiales, Universidad de Valencia, Valencia 46071, Spain; Email: Rafael.Abargues@uv.es

Sixto Giménez - Institute of Advanced Materials (INAM), Universitat Jaume I, Castelló de la Plana 12006, Spain; ○ orcid.org/0000-0002-4522-3174; Email: sjulia@uji.es

\section{Authors}

Jaume Noguera-Gómez - UMDO, Instituto de Ciencia de los Materiales, Universidad de Valencia, Valencia 46071, Spain

Miguel García-Tecedor - Institute of Advanced Materials (INAM), Universitat Jaume I, Castelló de la Plana 12006, Spain

Juan Francisco Sánchez-Royo - UMDO, Instituto de Ciencia de los Materiales, Universidad de Valencia, Valencia 46071, Spain; (1) orcid.org/0000-0002-4005-0884

Luisa María Valencia Liñán - Departamento de Ciencia de los Materiales e I. M. y Q. I Facultad de Ciencias, Universidad de Cádiz Campus Río San Pedro, Cádiz 11510, Spain

María de la Mata - Departamento de Ciencia de los Materiales e I. M. y Q. I Facultad de Ciencias, Universidad de 
Cádiz Campus Río San Pedro, Cádiz 11510, Spain; (1) orcid.org/0000-0002-1581-4838

Miriam Herrera-Collado - Departamento de Ciencia de los Materiales e I. M. y Q. I Facultad de Ciencias, Universidad de Cádiz Campus Río San Pedro, Cádiz 11510, Spain

Sergio I. Molina - Departamento de Ciencia de los Materiales e I. M. y Q. I Facultad de Ciencias, Universidad de Cádiz Campus Río San Pedro, Cádiz 11510, Spain

Complete contact information is available at: https://pubs.acs.org/10.1021/acsaem.1c00776

\section{Author Contributions \\ ${ }^{\perp}$ J.N.-G. and M.G.-T. contributed equally to this work. \\ Notes}

The authors declare no competing financial interest.

\section{ACKNOWLEDGMENTS}

The authors acknowledge the financial support from the Ministerio de Ciencia, Innovación y Universidades of Spain through funded projects ENE2017-85087-C3-1-R, RYC-201518349, and TEC2017-86102-C2-1-R and Agencia Valenciana de la Innovacion (AVI) INNVAL10/18/032. The authors thank the Central Support Service for Experimental Research (SCSIE) (XRD and SEM facilities) and the Institute of Materials Science (TGA and DTA equipment) of the University of Valencia and the Central Service of Scientific Instrumentation (SCIC) at University Jaume I. The authors also thank Prof. Juan P. Martinez-Pastor for his constructive suggestions and scientific discussions.

\section{REFERENCES}

(1) Kim, J. H.; Hansora, D.; Sharma, P.; Jang, J.-W.; Lee, J. S. Toward practical solar hydrogen production - an artificial photosynthetic leaf-to-farm challenge. Chem. Soc. Rev. 2019, 48, 19081971.

(2) De Luna, P.; Hahn, C.; Higgins, D.; Jaffer, S. A.; Jaramillo, T. F.; Sargent, E. H. What would it take for renewably powered electrosynthesis to displace petrochemical processes? Science 2019, 364, eaav3506.

(3) Sayama, K. Production of High-Value-Added Chemicals on Oxide Semiconductor Photoanodes under Visible Light for Solar Chemical-Conversion Processes. ACS Energy Lett. 2018, 3, 10931101.

(4) You, B.; Sun, Y. Innovative Strategies for Electrocatalytic Water Splitting. Acc. Chem. Res. 2018, 51, 1571-1580.

(5) Trasatti, S. Electrocatalysis by oxides - Attempt at a unifying approach. J. Electroanal. Chem. Interfacial Electrochem. 1980, 111, $125-131$.

(6) Lee, Y.; Suntivich, J.; May, K. J.; Perry, E. E.; Shao-Horn, Y. Synthesis and Activities of Rutile $\mathrm{IrO}_{2}$ and $\mathrm{RuO}_{2}$ Nanoparticles for Oxygen Evolution in Acid and Alkaline Solutions. J. Phys. Chem. Lett. 2012, 3, 399-404.

(7) Vij, V.; Sultan, S.; Harzandi, A. M.; Meena, A.; Tiwari, J. N.; Lee, W.-G.; Yoon, T.; Kim, K. S. Nickel-Based Electrocatalysts for EnergyRelated Applications: Oxygen Reduction, Oxygen Evolution, and Hydrogen Evolution Reactions. ACS Catal. 2017, 7, 7196-7225.

(8) De Silva, U.; Masud, J.; Zhang, N.; Hong, Y.; Liyanage, W. P. R.; Asle Zaeem, M.; Nath, M. Nickel telluride as a bifunctional electrocatalyst for efficient water splitting in alkaline medium. J. Mater. Chem. A 2018, 6, 7608-7622.

(9) Trześniewski, B. J.; Diaz-Morales, O.; Vermaas, D. A.; Longo, A.; Bras, W.; Koper, M. T. M.; Smith, W. A. In Situ Observation of Active Oxygen Species in Fe-Containing Ni-Based Oxygen Evolution Catalysts: The Effect of $\mathrm{pH}$ on Electrochemical Activity. J. Am. Chem. Soc. 2015, 137, 15112-15121.
(10) Fabbri, E.; Habereder, A.; Waltar, K.; Kötz, R.; Schmidt, T. J. Developments and perspectives of oxide-based catalysts for the oxygen evolution reaction. Catal. Sci. Technol. 2014, 4, 3800-3821.

(11) Park, J. H.; Seo, J.; Park, S.; Shin, S. S.; Kim, Y. C.; Jeon, N. J.; Shin, H.-W.; Ahn, T. K.; Noh, J. H.; Yoon, S. C.; Hwang, C. S.; Seok, S. I. Efficient $\mathrm{CH}_{3} \mathrm{NH}_{3} \mathrm{PbI}_{3}$ Perovskite Solar Cells Employing Nanostructured p-Type $\mathrm{NiO}$ Electrode Formed by a Pulsed Laser Deposition. Adv. Mater. 2015, 27, 4013-4019.

(12) Miller, E. L.; Rocheleau, R. E. Electrochemical behavior of reactively sputtered iron-doped nickel oxide. J. Electrochem. Soc. 1997, 144, 3072-3077.

(13) Ng, J. W. D.; García-Melchor, M.; Bajdich, M.; Chakthranont, P.; Kirk, C.; Vojvodic, A.; Jaramillo, T. F. Gold-supported ceriumdoped $\mathrm{NiO}_{x}$ catalysts for water oxidation. Nat. Energy 2016, 1, 16053.

(14) Joya, K. S.; Joya, Y. F.; de Groot, H. J. M. Ni-Based Electrocatalyst for Water Oxidation Developed In-Situ in a $\mathrm{HCO}_{3}{ }^{-1} \mathrm{CO}_{2}$ System at Near-Neutral pH. Adv. Energy Mater. 2014, 4, 1301929

(15) Park, I. J.; Kang, G.; Park, M. A.; Kim, J. S.; Seo, S. W.; Kim, D. H.; Zhu, K.; Park, T.; Kim, J. Y. Highly Efficient and Uniform $1 \mathrm{~cm}^{2}$ Perovskite Solar Cells with an Electrochemically Deposited $\mathrm{NiO}_{x}$ Hole-Extraction Layer. ChemSusChem 2017, 10, 2660-2667.

(16) Katumba, G.; Lu, J.; Olumekor, L.; Westin, G.; Wäckelgård, E. Low Cost Selective Solar Absorber Coatings: Characteristics of Carbon-In-Silica Synthesized with Sol-Gel Technique. J. Sol-Gel Sci. Technol. 2005, 36, 33-43.

(17) Smith, R. D. L.; Prévot, M. S.; Fagan, R. D.; Zhang, Z.; Sedach, P. A.; Siu, M. K. J.; Trudel, S.; Berlinguette, C. P. Photochemical Route for Accessing Amorphous Metal Oxide Materials for Water Oxidation Catalysis. Science 2013, 340, 60.

(18) Zhou, D.; Wang, S.; Jia, Y.; Xiong, X.; Yang, H.; Liu, S.; Tang, J.; Zhang, J.; Liu, D.; Zheng, L.; Kuang, Y.; Sun, X.; Liu, B. NiFe Hydroxide Lattice Tensile Strain: Enhancement of Adsorption of Oxygenated Intermediates for Efficient Water Oxidation Catalysis. Angew. Chem., Int. Ed. 2019, 58, 736-740.

(19) Zhou, H.; Yu, F.; Zhu, Q.; Sun, J.; Qin, F.; Yu, L.; Bao, J.; Yu, Y.; Chen, S.; Ren, Z. Water splitting by electrolysis at high current densities under 1.6 volts. Energy Environ. Sci. 2018, 11, 2858-2864.

(20) Zhang, B.; Zheng, X.; Voznyy, O.; Comin, R.; Bajdich, M.; García-Melchor, M.; Han, L.; Xu, J.; Liu, M.; Zheng, L.; García de Arquer, F. P.; Dinh, C. T.; Fan, F.; Yuan, M.; Yassitepe, E.; Chen, N.; Regier, T.; Liu, P.; Li, Y.; De Luna, P.; Janmohamed, A.; Xin, H. L.; Yang, H.; Vojvodic, A.; Sargent, E. H. Homogeneously dispersed multimetal oxygen-evolving catalysts. Science 2016, 352, 333.

(21) Duan, H.; Chen, Z.; Xu, N.; Qiao, S.; Chen, G.; Li, D.; Deng, W.; Jiang, F. Non-stoichiometric $\mathrm{NiO}_{\mathrm{x}}$ nanocrystals for highly efficient electrocatalytic oxygen evolution reaction. J. Electroanal. Chem. 2021, $885,114966$.

(22) Shudo, Y.; Fukuda, M.; Islam, M. S.; Kuroiwa, K.; Sekine, Y.; Karim, M. R.; Hayami, S. 3D porous $\mathrm{Ni} / \mathrm{NiO}_{x}$ as a bifunctional oxygen electrocatalyst derived from freeze-dried $\mathrm{Ni}(\mathrm{OH})_{2}$. Nanoscale 2021, 5530 .

(23) Fragua, D.; Noguera-Gomez, J.; Rodríguez-Canto, P. J.; Valencia, L. M.; de la Mata, M.; Herrera, M.; Molina, S. I.; Abargues, $\mathrm{R} . \mathrm{Au}-\mathrm{NiO}_{x}$ nanocomposite for hot electron-assisted plasmonic photocatalysis. J. Mater. Chem. C 2020, 8, 9885-9897.

(24) Rao, K. V.; Smakula, A. Dielectric Properties of Cobalt Oxide, Nickel Oxide, and Their Mixed Crystals. J. Appl. Phys. 1965, 36, 2031-2038.

(25) Lyons, M. E.; Brandon, M. P. The Oxygen Evolution Reaction on Passive Oxide Covered Transition Metal Electrodes in Aqueous Alkaline Solution. Part 1-Nickel. Int. J. Electrochem. Sci. 2018, 3, 1386-1424.

(26) Shinagawa, T.; Garcia-Esparza, A. T.; Takanabe, K. Insight on Tafel slopes from a microkinetic analysis of aqueous electrocatalysis for energy conversion. Sci. Rep. 2015, 5, 13801.

(27) Zhou, X.; Xia, Z.; Zhang, Z.; Ma, Y.; Qu, Y. One-step synthesis of multi-walled carbon nanotubes/ultra-thin $\mathrm{Ni}(\mathrm{OH})_{2}$ nanoplate 
composite as efficient catalysts for water oxidation. J. Mater. Chem. A 2014, 2, 11799-11806.

(28) Doyle, R. L.; Lyons, M. E. G. The Oxygen Evolution Reaction: Mechanistic Concepts and Catalyst Design. In Photoelectrochemical Solar Fuel Production: From Basic Principles to Advanced Devices; Giménez, S., Bisquert, J. Eds.; Springer International Publishing: Cham, 2016; pp. 41-104.

(29) Rakshit, S.; Ghosh, S.; Chall, S.; Mati, S. S.; Moulik, S. P.; Bhattacharya, S. C. Controlled synthesis of spin glass nickel oxide nanoparticles and evaluation of their potential antimicrobial activity: a cost effective and eco friendly approach. RSC Adv. 2013, 3, 1934819356.

(30) Yang, Y.; Fei, H.; Ruan, G.; Xiang, C.; Tour, J. M. Efficient electrocatalytic oxygen evolution on amorphous nickel-cobalt binary oxide nanoporous layers. ACS Nano 2014, 8, 9518-9523.

(31) Nsanzimana, J. M. V.; Dangol, R.; Reddu, V.; Duo, S.; Peng, Y.; Dinh, K. N.; Huang, Z.; Yan, Q.; Wang, X. Facile synthesis of amorphous ternary metal borides-reduced graphene oxide hybrid with superior oxygen evolution activity. ACS Appl. Mater. Interfaces 2018, 11, 846-855.

(32) Tian, T.; Zheng, M.; Lin, J.; Meng, X.; Ding, Y. Amorphous $\mathrm{Ni}-\mathrm{Fe}$ double hydroxide hollow nanocubes enriched with oxygen vacancies as efficient electrocatalytic water oxidation catalysts. Chem. Commun. 2019, 55, 1044-1047.

(33) Qiu, Y.; Xin, L.; Li, W. Electrocatalytic Oxygen Evolution over Supported Small Amorphous $\mathrm{Ni}-\mathrm{Fe}$ Nanoparticles in Alkaline Electrolyte. Langmuir 2014, 30, 7893-7901.

(34) Bickley, R. I.; Edwards, H. G. M.; Rose, S. J.; Gustar, R. A raman spectroscopic study of nickel(II) acetate, $\mathrm{Ni}\left(\mathrm{CH}_{3} \mathrm{COO}\right)_{2}$ and its aqueous and methanolic solutions. J. Mol. Struct. 1990, 238, 1526.

(35) Mironova-Ulmane, N.; Kuzmin, A.; Steins, I.; Grabis, J.; Sildos, I.; Pärs, M. Raman scattering in nanosized nickel oxide NiO. J. Phys.: Conf. Ser. 2007, 93, No. 012039.

(36) George, G.; Anandhan, S. Synthesis and characterisation of nickel oxide nanofibre webs with alcohol sensing characteristics. RSC Adv. 2014, 4, 62009-62020.

(37) Mironova-Ulmane, N.; Kuzmin, A.; Sildos, I.; Pärs, M. Polarisation dependent Raman study of single-crystal nickel oxide. Cent. Eur. J. Phys. 2011, 9, 1096.

(38) Karthikeyan, B.; Pandiyarajan, T.; Hariharan, S.; Ollakkan, M. $\mathrm{S}$. Wet chemical synthesis of diameter tuned $\mathrm{NiO}$ microrods: microstructural, optical and optical power limiting applications. CrystEngComm 2016, 18, 601-607.

(39) Kumari, L.; Li, W. Z.; Vannoy, C. H.; Leblanc, R. M.; Wang, D. Z. Vertically aligned and interconnected nickel oxide nanowalls fabricated by hydrothermal route. Cryst. Res. Technol. 2009, 44, 495499.

(40) Hammad, A. H.; Abdel-wahab, M. S.; Vattamkandathil, S.; Ansari, A. R. Influence the oxygen flow rate on the film thickness, structural, optical and photoluminescence behavior of DC sputtered $\mathrm{NiO}_{x}$ thin films. Phys. B 2019, 568, 6-12.

(41) Zhang, X.; Du, X. Oxygen vacancies confined in nickel oxide nanoprism arrays for promoted electrocatalytic water splitting. New J. Chem. 2020, 44, 1703-1706.

(42) Eichel, R.-A. Structural and dynamic properties of oxygen vacancies in perovskite oxides-analysis of defect chemistry by modern multi-frequency and pulsed EPR techniques. Phys. Chem. Chem. Phys. 2011, 13, 368-384.

(43) Prades, J. D.; Arbiol, J.; Cirera, A.; Morante, J. R.; Avella, M.; Zanotti, L.; Comini, E.; Faglia, G.; Sberveglieri, G. Defect study of $\mathrm{SnO}_{2}$ nanostructures by cathodoluminescence analysis: Application to nanowires. Sens. Actuators, B 2007, 126, 6-12.

(44) Corby, S.; Francàs, L.; Kafizas, A.; Durrant, J. R. Determining the role of oxygen vacancies in the photoelectrocatalytic performance of $\mathrm{WO}_{3}$ for water oxidation. Chem. Sci. 2020, 11, 2907-2914.

(45) Francàs, L.; Corby, S.; Selim, S.; Lee, D.; Mesa, C. A.; Godin, R.; Pastor, E.; Stephens, I. E. L.; Choi, K.-S.; Durrant, J. R.
Spectroelectrochemical study of water oxidation on nickel and iron oxyhydroxide electrocatalysts. Nat. Commun. 2019, 10, 5208.

(46) Kang, Q.; Cao, J.; Zhang, Y.; Liu, L.; Xu, H.; Ye, J. Reduced $\mathrm{TiO}_{2}$ nanotube arrays for photoelectrochemical water splitting. $J$. Mater. Chem. A 2013, 1, 5766-5774.

(47) Zhang, K.; Ravishankar, S.; Ma, M.; Veerappan, G.; Bisquert, J.; Fabregat-Santiago, F.; Park, J. H. Overcoming Charge Collection Limitation at Solid/Liquid Interface by a Controllable Crystal Deficient Overlayer. Adv. Energy Mater. 2017, 7, 1600923.

(48) Jana, S.; Samai, S.; Mitra, B. C.; Bera, P.; Mondal, A. Nickel oxide thin film from electrodeposited nickel sulfide thin film: peroxide sensing and photo-decomposition of phenol. Dalton Trans. 2014, 43, 13096-13104.

(49) Zhang, Z.; Zhao, Y.; Zhu, M. NiO films consisting of vertically aligned cone-shaped $\mathrm{NiO}$ rods. Appl. Phys. Lett. 2006, 88, No. 033101.

(50) Wang, S.; Ge, X.; Lv, C.; Hu, C.; Guan, H.; Wu, J.; Wang, Z.; Yang, X.; Shi, Y.; Song, J.; Zhang, Z.; Watanabe, A.; Cai, J. Oxygen vacancy-rich amorphous porous $\mathrm{NiFe}(\mathrm{OH})_{x}$ derived from $\mathrm{Ni}(\mathrm{OH})_{x} /$ Prussian blue as highly efficient oxygen evolution electrocatalysts. Nanoscale 2020, 12, 9557-9568.

(51) Kim, N.; Lim, D.; Choi, Y.; Shim, S. E.; Baeck, S.-H. Hexagonal $\beta-\mathrm{Ni}(\mathrm{OH})_{2}$ nanoplates with oxygen vacancies as efficient catalysts for the oxygen evolution reaction. Electrochim. Acta 2019, 324, 134868.

(52) Wochnik, A. S.; Handloser, M.; Durach, D.; Hartschuh, A.; Scheu, C. Increasing crystallinity for improved electrical conductivity of $\mathrm{TiO}_{2}$ blocking layers. ACS Appl. Mater. Interfaces 2013, 5, 56965699.

(53) Liang, Y.; Sherwood, P. M. A.; Paul, D. K. Valence and core photoemission of the films formed electrochemically on nickel in sulfuric acid. J. Chem. Soc., Faraday Trans. 1994, 90, 1271-1278.

(54) Grosvenor, A. P.; Biesinger, M. C.; Smart, R. S. C.; McIntyre, N. S. New interpretations of XPS spectra of nickel metal and oxides. Surf. Sci. 2006, 600, 1771-1779.

(55) Payne, B. P.; Biesinger, M. C.; McIntyre, N. S. The study of polycrystalline nickel metal oxidation by water vapour. J. Electron Spectrosc. Relat. Phenom. 2009, 175, 55-65.

(56) Weidler, N.; Schuch, J.; Knaus, F.; Stenner, P.; Hoch, S.; Maljusch, A.; Schäfer, R.; Kaiser, B.; Jaegermann, W. X-ray Photoelectron Spectroscopic Investigation of Plasma-Enhanced Chemical Vapor Deposited $\mathrm{NiO}_{x}, \mathrm{NiO}_{x}(\mathrm{OH})_{y}$, and $\mathrm{CoNiO}_{x}(\mathrm{OH})_{y}$ : Influence of the Chemical Composition on the Catalytic Activity for the Oxygen Evolution Reaction. J. Phys. Chem. C 2017, 121, 64556463.

(57) Cai, W.; Chen, R.; Yang, H.; Tao, H. B.; Wang, H.-Y.; Gao, J.; Liu, W.; Liu, S.; Hung, S.-F.; Liu, B. Amorphous versus Crystalline in Water Oxidation Catalysis: A Case Study of NiFe Alloy. Nano Lett. 2020, 20, 4278-4285.

(58) Corby, S.; Tecedor, M.-G.; Tengeler, S.; Steinert, C.; Moss, B.; Mesa, C. A.; Heiba, H. F.; Wilson, A. A.; Kaiser, B.; Jaegermann, W.; Francàs, L.; Gimenez, S.; Durrant, J. R. Separating bulk and surface processes in $\mathrm{NiO}_{x}$ electrocatalysts for water oxidation. Sustainable Energy Fuels 2020, 5024.

(59) Nakaoka, K.; Ueyama, J.; Ogura, K. Semiconductor and electrochromic properties of electrochemically deposited nickel oxide films. J. Electroanal. Chem. 2004, 571, 93-99.

(60) Bera, B.; Chakraborty, A.; Kar, T.; Leuaa, P.; Neergat, M. Density of States, Carrier Concentration, and Flat Band Potential Derived from Electrochemical Impedance Measurements of N-Doped Carbon and Their Influence on Electrocatalysis of Oxygen Reduction Reaction. J. Phys. Chem. C 2017, 121, 20850-20856.

(61) Yang, H. B.; Miao, J.; Hung, S.-F.; Chen, J.; Tao, H. B.; Wang, X.; Zhang, L.; Chen, R.; Gao, J.; Chen, H. M.; Dai, L.; Liu, B. Identification of catalytic sites for oxygen reduction and oxygen evolution in $\mathrm{N}$-doped graphene materials: Development of highly efficient metal-free bifunctional electrocatalyst. Sci. Adv. 2016, 2, No. e1501122.

(62) Gimenez, S.; Dunn, H. K.; Rodenas, P.; Fabregat-Santiago, F.; Miralles, S. G.; Barea, E. M.; Trevisan, R.; Guerrero, A.; Bisquert, J. 
Carrier density and interfacial kinetics of mesoporous $\mathrm{TiO}_{2}$ in aqueous electrolyte determined by impedance spectroscopy. J. Electroanal. Chem. 2012, 668, 119-125.

(63) Bisquert, J. Chemical capacitance of nanostructured semiconductors: its origin and significance for nanocomposite solar cells. Phys. Chem. Chem. Phys. 2003, 5, 5360-5364.

(64) Almora, O.; Garcia-Belmonte, G. Light capacitances in silicon and perovskite solar cells. Solar Energy 2019, 189, 103-110.

(65) Boix, P. P.; Ajuria, J.; Etxebarria, I.; Pacios, R.; GarciaBelmonte, G.; Bisquert, J. Role of $\mathrm{ZnO}$ Electron-Selective Layers in Regular and Inverted Bulk Heterojunction Solar Cells. J. Phys. Chem. Lett. 2011, 2, 407-411.

(66) Zhang, Y.; Zeng, Z.; Ho, D. Mn dopant induced high-valence $\mathrm{Ni}^{3+}$ sites and oxygen vacancies for enhanced water oxidation. Mater. Chem. Front. 2020, 4, 1993-1999.

(67) Dong, C.; Liu, Z.-W.; Liu, J.-Y.; Wang, W.-C.; Cui, L.; Luo, R.C.; Guo, H.-L.; Zheng, X.-L.; Qiao, S.-Z.; Du, X.-W.; Yang, J. Modest Oxygen-Defective Amorphous Manganese-Based Nanoparticle Mullite with Superior Overall Electrocatalytic Performance for Oxygen Reduction Reaction. Small 2017, 13, 1603903.

(68) Xu, B.; Xia, L.; Zhou, F.; Zhao, R.; Chen, H.; Wang, T.; Zhou, Q.; Liu, Q.; Cui, G.; Xiong, X.; Gong, F.; Sun, X. Enhancing electrocatalytic $\mathrm{N}_{2}$ reduction to $\mathrm{NH}_{3}$ by $\mathrm{CeO}_{2}$ nanorod with oxygen vacancies. ACS Sustainable Chem. Eng. 2019, 7, 2889-2893.

(69) Yang, W.; Yang, X.; Jia, J.; Hou, C.; Gao, H.; Mao, Y.; Wang, C.; Lin, J.; Luo, X. Oxygen vacancies confined in ultrathin nickel oxide nanosheets for enhanced electrocatalytic methanol oxidation. Appl. Catal., B 2019, 244, 1096-1102.

(70) Zhang, B.; Wang, L.; Zhang, Y.; Ding, Y.; Bi, Y. Ultrathin $\mathrm{FeOOH}$ nanolayers with abundant oxygen vacancies on $\mathrm{BiVO}_{4}$ photoanodes for efficient water oxidation. Angew. Chem., Int. Ed. 2018, 57, 2248-2252.

(71) Fernández-Climent, R.; Giménez, S.; García-Tecedor, M. The Role of Oxygen Vacancies on Water Splitting Photoanodes. Sustainable Energy Fuels 2020, 4, 5916-5926.

(72) He, C.; Huang, M.; Wang, G.; Zhang, Y.; Li, X.; Fan, L.; Li, Y. Synergistic tuning of oxygen vacancies and d-band centers of ultrathin cobaltous dihydroxycarbonate nanowires for enhanced electrocatalytic oxygen evolution. Nanoscale 2020, 12, 11735-11745.

(73) Asnavandi, M.; Yin, Y.; Li, Y.; Sun, C.; Zhao, C. Promoting oxygen evolution reactions through introduction of oxygen vacancies to benchmark $\mathrm{NiFe}-\mathrm{OOH}$ catalysts. ACS Energy Lett. 2018, 3, 15151520.

(74) Zhuang, L.; Jia, Y.; He, T.; Du, A.; Yan, X.; Ge, L.; Zhu, Z.; Yao, $\mathrm{X}$. Tuning oxygen vacancies in two-dimensional iron-cobalt oxide nanosheets through hydrogenation for enhanced oxygen evolution activity. Nano Res. 2018, 11, 3509-3518.

(75) Trotochaud, L.; Young, S. L.; Ranney, J. K.; Boettcher, S. W. Nickel-iron oxyhydroxide oxygen-evolution electrocatalysts: the role of intentional and incidental iron incorporation. J. Am. Chem. Soc. 2014, 136, 6744-6753.

(76) Klaus, S.; Cai, Y.; Louie, M. W.; Trotochaud, L.; Bell, A. T. Effects of Fe electrolyte impurities on $\mathrm{Ni}(\mathrm{OH})_{2} / \mathrm{NiOOH}$ structure and oxygen evolution activity. J. Phys. Chem. C 2015, 119, 72437254.

(77) Louie, M. W.; Bell, A. T. An Investigation of Thin-Film Ni-Fe Oxide Catalysts for the Electrochemical Evolution of Oxygen. J. Am. Chem. Soc. 2013, 135, 12329-12337.

(78) Costa, I. M.; Colmenares, Y. N.; Pizani, P. S.; Leite, E. R.; Chiquito, A. J. Sb doping of VLS synthesized $\mathrm{SnO}_{2}$ nanowires probed by Raman and XPS spectroscopy. Chem. Phys. Lett. 2018, 695, 125130.

(79) Haddad, N.; Ben Ayadi, Z.; Mahdhi, H.; Djessas, K. Influence of fluorine doping on the microstructure, optical and electrical properties of $\mathrm{SnO}_{2}$ nanoparticles. J. Mater. Sci.: Mater. Electron. 2017, $28,15457-15465$.

(80) García-Tecedor, M.; Maestre, D.; Cremades, A.; Piqueras, J. Growth and characterization of $\mathrm{Cr}$ doped $\mathrm{SnO}_{2}$ microtubes with resonant cavity modes. J. Mater. Chem. C 2016, 4, 5709-5716.
(81) Chemelewski, W. D.; Lee, H.-C.; Lin, J.-F.; Bard, A. J.; Mullins, C. B. Amorphous FeOOH Oxygen Evolution Reaction Catalyst for Photoelectrochemical Water Splitting. J. Am. Chem. Soc. 2014, 136, $2843-2850$. 